\title{
The effect of nocturia on sleep
}

\author{
Sonia Ancoli-Israel ${ }^{1,{ }^{*}, \text { Donald L. Bliwise }}{ }^{2}$, and Jens Peter Nørgaard ${ }^{3}$ \\ ${ }^{1}$ Professor of Psychiatry, Department of Psychiatry, University of California, San Diego, 9500 \\ Gilman Drive \#0733, San Diego, CA 92093-0733, USA \\ ${ }^{2}$ Professor of Neurology, Psychiatry/Behavioral Sciences, and Nursing; Director, Program in \\ Sleep, Aging and Chronobiology, Emory University School of Medicine, Wesley Woods Health \\ Center, 1841 Clifton Road, Room 509, Atlanta, Georgia 30329, USA Phone : 404-728-4751; \\ FAX: 404-728-4756 ; dbliwis@emory.edu \\ ${ }^{3}$ Chief Scientific Officer Urology, Ferring Pharmaceuticals A/S, Medical Science Urology \\ International Pharmascience Center, Kay Fiskers Plads 11 DK- 2300 Copenhagen S, and Adjunct \\ Professor of Urology, University of Lund, Sweden Phone +45 2878 7547; FAX: +45 28176548; \\ JensPeter.Norgaard@ferring.com
}

\begin{abstract}
Sleep plays a vital role in physical and mental functioning. It is increasingly recognized that disturbed sleep is a highly prevalent and chronic condition that merits greater awareness due to the wide-ranging and serious repercussions associated with it. Nocturia is one of the causes of sleep disturbance and has been shown to impair functioning, quality of life, health and productivity, with those experiencing two or more voids per night reporting significant 'bother'. Nocturia warrants full consideration as a significant target for intervention, aiming to reduce the burden of disturbed sleep on individuals, families and society. Currently however, a definitive evaluation of the most relevant sleep endpoints in nocturia therapy is lacking. One endpoint often used is the duration of the initial sleep period, which when evaluated in combination with the number of voiding episodes per night might be an indication of the severity of sleep disruption in patients with nocturia.
\end{abstract}

\section{Keywords}

nocturia; sleep; insomnia; quality of life

\section{Introduction}

The importance of good sleep has only begun to be understood. It has been known for many years that a good night's sleep is important, with 7-8 hours endorsed for adults. New data reinforce the increased risks associated with insufficient sleep. In a series of studies by Stone and associates on older men and women, ${ }^{1-5}$ less sleep at night and lower sleep efficiency (defined as the amount of sleep given the amount of time in bed) were both associated with increased risk of poor physical function, decreased cognitive function, falls and mortality.

\footnotetext{
*Corresponding author Phone: 858 822-7710 ; Fax: 858 822-7712 ; sancoliisrael@ucsd.edu.

Disclosures: [information to be transferred to COI forms]

Sonia Ancoli-Israel, Ph.D: Consultant/Scientific Advisory Board: Ferring Pharmaceuticals Inc., GlaxoSmithKline, Merck, Orphagen Pharmaceuticals, Pfizer, Respironics, sanofiaventis, Sepracor, Inc., Schering-Plough. Grants/Contracts: Sepracor, Inc., Litebook, Inc Donald L. Bliwise, PhD has no conflicts of interest

Jens Peter Nørgaard MD DMSC: Full time employee at Ferring Pharmaceuticals In Copenhagen, Denmark
} 
There are many reasons why sleep can be disrupted or shortened at night, including primary sleep disorders, changes in circadian rhythms, or just not spending enough time in bed. In addition, both exogenous and endogenous factors can disrupt sleep, such as too much light or noise in the bedroom. The sensation of a full bladder may also cause awakening and ultimately lead to the conscious decision to get out of bed to go to the bathroom; when this happens multiple times during the night, it is defined as nocturia. .

\section{What is 'disturbed sleep'?}

Disturbed sleep can mean many things but it is often equated with insomnia, which is clinically defined as persistent difficulty in initiating or maintaining sleep, or non-restorative sleep, that causes significant daytime distress and impaired social or occupational functioning. ${ }^{6}$ Insomnia affects around $15 \%$ of adults and is among the most prevalent chronic disorder in the general population. ${ }^{7}$ Three types of insomnia have been characterized: sleep onset insomnia (difficulty falling asleep), sleep maintenance insomnia (frequent night-time awakenings), and early morning insomnia (awakening early in the morning and being unable to return to sleep). ${ }^{7}$ Sleep maintenance insomnia is most frequently reported in older adults. In a recent survey of close to 9000 adults representative of the US general population, one-third of respondents experienced nocturnal awakening at least 3 times per week, and $23 \%$ reported awakening every night. ${ }^{8} \mathrm{~A}$ high proportion of respondents reporting nocturnal awakenings woke up at least twice per night (59\%), and nearly half of all respondents had difficulty resuming sleep once awake (43\%). ${ }^{8}$ This difficulty returning to sleep is associated with stronger impairment of daytime functioning, particularly daytime sleepiness. Significantly, daytime sleepiness was approximately twice as prevalent in respondents reporting nocturnal awakenings when compared with those who did not report awakenings $(P<0.0001) .{ }^{8}$ In the vast majority of respondents $(90 \%)$, nocturnal awakenings were chronic in nature, with the problem lasting more than 6 months. The diagnosis and treatment of insomnia is complex, largely due to the varying nature of the condition and its etiology. Broadly speaking, however, insomnia can occur independently, i.e., primary insomnia, or in conjunction with a medical or psychiatric condition, in which case it is classified as co-morbid insomnia. ${ }^{9}$ Notably, $66-75 \%$ of all insomnia-related complaints are attributed to co-morbid insomnia. ${ }^{7}$

\section{Insomnia Co-Morbid with Nocturia}

Disturbed sleep, or insomnia, is often co-morbid with nocturia, i.e., the sensation of a full bladder leading to the need to get up to urinate at night. ${ }^{10,11}$ Three-quarters of participants in a survey of US residents aged 18 years or over cited the need to go to the bathroom as the most frequent reason for nocturnal awakenings. ${ }^{8}$ Indeed, going to the toilet was the primary reason for night-time awakening across all age groups, and the proportion affected increased with age: $39.9 \%$ in those aged $18-44$ years to $77.1 \%$ in those aged 65 or above (Figure 1). ${ }^{8}$ Other causes of night-time awakenings such as spontaneous awakening, being bothered by a bed partner, being awakened by a child, due to thirst or due to a dream were reported less frequently and their prevalence decreased with age (Figure 1).

Data from the United States' National Sleep Foundation 2003 survey corroborate these findings. The survey specifically assessed the prevalence of nocturia among older age groups self-reporting insomnia $(N=1424) .{ }^{10}$ The results showed that more than half (53\%) of respondents aged 55-84 years perceived nocturia as the cause of disturbed sleep 'every night or almost every night'; this was 4-fold higher than the proportion reporting pain, which was the next most common reason for sleep disturbance (12\%). Nocturia was shown to be an independent predictor of self-reported insomnia (odds ratio [OR] 1.75; 95\% confidence interval $[\mathrm{CI}] 1.31,2.35)$ and deterioration in sleep quality (OR $1.71 ; 95 \% \mathrm{CI} 1.31,2.23) .{ }^{10}$ 
Study findings such as these highlight the need for greater awareness of the impact of bladder sensations and ultimately nocturia on sleep, and the implications of repeated sleep disturbance on a person's daytime functioning. ${ }^{10}$

Several other studies have also reported that nocturia is associated with disrupted sleep. Cai et $\mathrm{a}^{12}$ reported that scores suggesting poor quality of sleep on most subscales of the Pittsburgh Sleep Quality Index (PSQI) correlated with severity of nocturia; similar findings of sleep disturbance were noted on the Nordic Sleep Questionnaire insomnia subscale. ${ }^{13}$ Using a sleep diary, Yoshimura et $\mathrm{al}^{14}$ found that nocturia was related specifically to more difficulty falling asleep, whereas $\mathrm{Yu}$ et $\mathrm{a}^{15}$ reported that nocturia was associated both with fewer total hours of sleep and to difficulty falling back to sleep during the night (sleep maintenance insomnia). Although none of these studies used any objective sleep measures, they nonetheless provide compelling evidence that nightly awakenings to void are highly disruptive to an individual's sleep.

\section{What is the real-life burden of 'disturbed sleep' and nocturia?}

\section{The individual}

Quality of life-Chronic lack of sleep can have a great impact on ability to function. Sleep disturbances which result in sleep deprivation can also exact an immense personal toll, as evidenced by the adverse impact of disturbed sleep on physical and emotional health as well as overall quality of life (QoL). Sleep disruption among insomnia sufferers has been associated with impairments in daytime functioning and cognition, and with increased medical illnesses, hospitalizations and work absences due to sickness. ${ }^{7}, 16,17$ The magnitude of daytime impairments is larger in patients with co-morbid insomnia, which includes conditions such as nocturia, than in those with primary insomnia, as shown by increased fatigue as well as cognitive problems and sleepiness. ${ }^{7}$ It is increasingly recognized that nocturia is a major cause of sleep disturbance affecting around $50 \%$ of adults ${ }^{18}$ and, therefore, may be a key contributor to reduced levels of QoL and functioning in a substantial proportion of the population. ${ }^{16,19,20}$

In one community study of 663 adults from Taiwan reporting at least one episode of nocturia every night, QoL was measured using the nocturia-specific quality of life (N-QOL) questionnaire (lower scores indicate poorer QoL; range 0-100). ${ }^{15}$ The results showed that QoL decreased with increasing episodes of nocturia (mean N-QOL scores were 91.4, 83.7, 77.6, and 67.6 for one, two, three, and four nocturia episodes, respectively). Importantly, the impact of nocturia on QoL was greatest for those experiencing at least two episodes per night. These findings were consistent with a US study of 1214 women, ${ }^{21}$ which showed that nocturia had a significant impact in patients with at least two night-time voids (as determined using Question 3 of the Symptom Problem Index: 'Over the past month, how much has getting up at night to urinate been a problem for you?'). A further study of 203 healthy professionally active people in Sweden demonstrated that nocturia is associated with significantly lower vitality and utility (frequently-used indicators of QoL). ${ }^{22}$ These data all suggest that irrespective of gender or professional or geographical background, nocturia adversely affects QoL. Furthermore, the causal relationship between nocturia and sleep disturbance is underscored by the observation that the extent of sleep disturbance caused by nocturia is an independent predictor of lower QoL. ${ }^{15}$

It may be hypothesized that the patient-reported impact of nocturia should be greater in younger than in older patients since younger people are likely to have more active lifestyles and demanding schedules at work, factors particularly affected by disturbed sleep. While formal studies investigating this possibility are lacking, there is some limited evidence which may be consistent with such a theory. For instance, the association between nocturia 
and trouble sleep resulted in statistically significant effects that were $42 \%$ larger in 45-49 year old women relative to 60-64 year old women. ${ }^{23}$ In another study, bother of nocturia was reported to be greater by younger patients than older patients. ${ }^{23}$

Performance at work-The impact of nocturia on the individual also translates into adverse effects on occupational functioning. Similar to the impact of disturbed sleep, lower work productivity and increased sick leave have been reported in patients with nocturia. 8,22 In a telephone survey in the USA, frequent nocturnal awakenings were associated with significantly more days of sick leave (waking every night: 37.4 days; 5-6 nights per week: 36.4 ; $3-4$ nights per week: 33.3 ) compared with awakening fewer than 3 days per week $(26.6, P<0.001) .{ }^{8}$ In their study of professionally active individuals with nocturia, Kobelt et $\mathrm{al}^{22}$ showed that overall work impairment (as assessed by the Work Productivity and Activity Impairment questionnaire) significantly increased with increasing severity of nocturia $(P<0.05)$. It is possible that this kind of impaired performance and attendance at work may have consequences for the employability, earning potential and job stability of some people with nocturia.

Accidents-Traffic and workplace accidents are also a significant hazard in those experiencing sleep deprivation or disruption. ${ }^{24}$ Fatigue is estimated to be involved in $16-$ $60 \%$ of road accidents and driving after even moderate sleep deprivation is at least as dangerous as low-level alcohol intoxication. ${ }^{25}$ As a leading cause of sleep disruption, nocturia might play a role in fatigue in some drivers and workers, and thereby contribute to accidents on the road and in the workplace. Research is needed to test this hypothesis.

Falls and fractures among the elderly are another form of accident contributing to the morbidity and mortality associated with sleep disturbance and nocturia. As mentioned above, decreased total sleep time is associated with an increased risk of falls and fractures. ${ }^{2}$ There is also an increased likelihood of falls among older people with nocturia, ${ }^{26}$ which may arise directly from the necessity to make trips to the bathroom at night and/or sleepiness during the day. Studies have shown a significant positive association between the frequency of voiding each night and the prevalence of bone fractures, ${ }^{26,27}$ with two voids or more per night associated with a greater than 2-fold increase in the risk of fractures (hazard ratio [HR] $2.45,95 \%$ CI 1.08, 5.54) and fall-related fractures (HR 2.63, 95\% CI 1.05, 6.57) in one study. ${ }^{26}$ A recent study also found the increased risk of hip fractures in men with nocturia to be age-independent. ${ }^{28}$

Morbidity and mortality-Poor sleepers and patients with nocturia are reported to have increased morbidity. The majority of people with $\geq 2$ voids per night rate their health as poor or moderate..$^{29}$ In one study, poor health in women aged 40-64 years was positively correlated with the number of nocturnal voids, such that the prevalence of poor health approached $40 \%$ in women experiencing at least three nocturnal voids compared with 5\% in those women who did not report any night-time voids. ${ }^{30}$ This relationship may in part be due to an association between nocturia and other chronic conditions such as cardiovascular disease, diabetes, depression and sleep apnea. ${ }^{24,31-33}$

Poor sleepers and patients with nocturia are also reported to have increased mortality rates. Multivariate logistic models have demonstrated an increased mortality risk among patients in Japan reporting at least two night-time voids, even when controlling for co-morbidities or correlates, including diabetes, hypertension, coronary disease, nephropathy, alcohol consumption, history of childbirth, and use of tranquilizers, hypnotics and diuretics (HR $2.68,95 \%$ CI $1.12,6.43) .{ }^{34}$ Further studies in this area are warranted. 
Nocturia also may be associated with sleep apnea, and several potential mechanisms have been postulated to play a role. First, and perhaps most obvious, is that individuals with sleep apnea may awaken from an apneic episode, appreciate the need to void and then make a bathroom trip. Apart from such circumstances, however, several interacting biochemical mechanisms may also be involved. Sleep apnea is associated with decreased nocturnal plasma renin and aldosterone secretion, and treatment with nasal continuous positive airway pressure (CPAP) reverses these effects, as well as decreasing nocturnal diuresis and normalizing sodium output. Nocturnal diuresis may be partially mediated through enhanced release of atrial natriuretic peptide (ANP) and elevated sympathetic tone (as indexed by higher levels of norepinephrine, in particular), effects that also reverse with CPAP, although a role for ANP may be most readily apparent only in severe cases. Increased urine production in sleep apnea does not appear related to reductions in antidiuretic hormone, as CPAP has little effect on excretion of this peptide.

Several studies have demonstrated that prevalence of nocturia is elevated in those who are diagnosed with sleep apnea in sleep laboratories, ${ }^{31}$ as well as in more representative sampling from the general population who report nocturia and then are evaluated for breathing disorders in sleep. ${ }^{35}$ Sleep apnea, which is also a known cause of increased mortality, was not directly controlled for in the above Japanese analysis, although many of the conditions associated with sleep apnea - such as hypertension and coronary heart disease - were. These data suggest that there may be health consequences specifically related to nocturia and the sleep fragmentation caused by this condition, which are independent of comorbidities. Taken together, these studies suggest that sleep apnea should always be considered carefully as a specific sleep disorder that may be associated with nocturia. A number of studies have suggested that successful treatment of sleep apnea with continuous positive airway pressure may result in reduced levels of ANP and decreased nocturia episodes and/or decreased urine production (see below).

\section{Clinical evaluation of nocturia}

Nocturia is multifactorial and can be associated with serious medical conditions such as diabetes mellitus, diabetes insipidus and congestive heart failure. Once such underlying illnesses have been excluded through thorough history-taking and patient evaluation, other possible contributory factors need to be explored. A fundamental issue in most patients is that the amount of urine produced overnight exceeds the capacity of the bladder. This may be due to an overproduction of urine (nocturnal polyuria [NP], defined as a nocturnal urinary output - including the volume of the first void in the morning - of $>33 \%$ of the total daily output) ${ }^{11}$ or an inability of the bladder to store normal quantities of urine (reduced bladder capacity), or a combination of these factors. Nocturnal polyuria may indicate sleep apnea, or a blunted circadian rhythm of vasopressin release. Reduced bladder capacity may be caused by conditions such as overactive bladder, or benign prostatic obstruction in men. However, reduced bladder storage capacity is usually accompanied by daytime symptoms such as frequency and urgency. It is noteworthy that the prevalence of nocturia in women is as high as it is in men, despite the fact that women do not have a prostate, which suggests alternative etiologies affecting both men and women. A key tool in effective diagnosis of nocturia is the monitoring of voiding volumes as well as frequency. Frequency-volume charts, in which patients record this information over 3 days and nights, can greatly assist the clinician in differential diagnosis and the identification of NP, reduced bladder storage capacity, as well as cases where both of these factors contribute to nocturia. 


\section{Treatment of nocturia}

Before entering into discussion of available therapies for nocturia and their effect on subsequent sleep, it should first be highlighted that the question of which sleep endpoints are most relevant is as yet unresolved. Efficacy in nocturia trials is generally reported as the reduction in number of voids per night, or percentage reduction in voids per night, and QoL studies indicate that those people with fewer than two voids/night experience minimal impact on their daytime functioning. ${ }^{15,21}$ It is reasonable therefore to argue that treatment which reduces nocturnal voiding to this level or below is of clinical significance. But these are measures of nocturia and not of sleep. It is not clear which measure of sleep would be most informative, or what degree of change in sleep parameters would represent a genuine improvement for the patient. In many urological studies, a practical endpoint of sleep duration to the first void or first awakening is used. Even within this endpoint, there may be different methods or inconsistencies of data collection. For example, in such studies, does that initial sleep period begin when the subject goes to bed, when they turn off the light, or when sleep begins, or from the time from the patient's last void before he or she goes to bed? Does it include only time when the subject is asleep, or does it also include the time when they may be awake for a reason other than the need to void? Further questions arise as to whether there is a minimal duration of the initial sleep period above which the individual experiences benefits for health. Alternatively, are self-reported sleep quality measures most relevant for defining improvement?, Currently, a definitive evaluation of the most relevant sleep endpoints in nocturia therapy is lacking. However, the duration of the initial sleep bout would seem a reasonable and practical indication of the severity of sleep disruption in nocturia patients, especially if evaluated in combination with the number of voiding episodes per night. This measure of the initial sleep period duration has been used in several studies. ${ }^{36-38}$

There are a number of possible therapy options for nocturia, depending on the etiology of the condition. Urological causes of nocturia can be treated with anticholinergics (e.g., tolterodine, darifenacin, solifenacin), $\alpha$-blockers/ $\alpha$-adrenergic blockers (e.g., tamsulosin), or with desmopressin. Some studies report significant improvements in sleep with anticholinergics or $\alpha$-blockers. ${ }^{39,} 40$ Although such studies report changes in measures that suggest improvement in nocturia, some have used scales with uncertain significance. For example, one study reported an improvement of -3.85 in the sleep/energy domain of the King's Health Questionnaire (KHQ) with tolterodine versus placebo $(P=0.006) ;{ }^{41}$ however, this scale ranges from 0-100 and the relevance of such small improvements at this level is uncertain - the authors of the KHQ themselves suggest a change of $\geq 5$ points is needed before 'an important effect at the patient level' is suggested..$^{42}$ On the other hand, a study of darifenacin relying upon daily diaries ${ }^{39}$ reported a significant reduction in nocturnal awakenings due to micturition and/or incontinence and/or urgency. It should be noted that this reduction was reported as the number of voids per week, with a maximum median treatment difference versus placebo of -1.6 awakenings per week (from a baseline of 12.4); if this were crudely extrapolated to a nightly basis (as commonly reported in studies of nocturia therapy), this is would be roughly equivalent to a net benefit versus placebo of about 0.2 awakenings per night.

Nocturnal polyuria may cause nocturia as an isolated lower urinary tract symptom or may act in combination with bladder/prostate-related factors. It has been found to be present in between 58 and $88 \%$ of nocturia patients presenting for a large clinical trial of nocturia therapy, ${ }^{43}$ and its high prevalence should not be overlooked. As mentioned, nocturnal polyuria in turn may be caused by a blunted circadian rhythm of vasopressin release, or other issues such as sleep apnea, which should be ruled out or treated. Sleep apnea is known to lead to an increase in atrial natriuretic peptide, resulting in nocturnal natriuresis and 
consequently increased diuresis (solute diuresis) which does not respond to vasopressin receptor $2\left(\mathrm{~V}_{2}\right)$ agonist treatment (desmopressin). ${ }^{44} \mathrm{~A}$ number of studies have shown a decrease in nocturia episodes and/or nocturnal urine production with continuous positive airflow pressure therapy treatment for sleep apnea. ${ }^{45,46}$ In other patients with NP and a dilute diuresis, antidiuretic therapy may be effective. Desmopressin is a synthetic analogue of the naturally-occurring antidiuretic hormone, arginine vasopressin, and it has been found to be an effective treatment in nocturia patients, ${ }^{44}$ with mean number of voids per night reduced to less than two on average. ${ }^{47-49}$ Reductions in nocturia frequency with treatment are accompanied by a significant increase in the hours of undisturbed sleep ${ }^{50}$ (Figure 2), and a lengthening of the initial sleep period compared with placebo. ${ }^{38,47,48}$ During the doubleblind treatment phase of one 3-week study, 27\% of patients achieved more than $5 \mathrm{~h}$ of unbroken sleep compared with only $9 \%$ of placebo-treated patients. ${ }^{38}$ In a large long-term study, the first sleep period was significantly prolonged from 157 to 288 minutes in men and 142 to 310 minutes in women. ${ }^{49}$ Moreover, active treatment improved daytime freshness (i.e. in response to the question "During the last week, did you often feel fresh in the mornings?") significantly more than placebo $(\mathrm{p}=0.02) .{ }^{38}$

A small number of studies have attempted to treat nocturia by targeting the brain rather than the bladder, with the hypothesis that nocturia in some patients may be attributable to sleep fragmentation causing the patient to wake up and then go to the toilet because they are awake. For example, Song and $\mathrm{Ku}^{51}$ showed that an $\alpha$-blocker combined with zolpidem reduced subjectively reported nocturia episodes more successfully than the $\alpha$-blocker alone, but there was no placebo control group in this study. Another uncontrolled study by Sugaya et al ${ }^{52}$ found that increased physical activity, itself an intervention known to solidify sleep, ${ }^{53}$ successfully reduced nocturia. There is some limited evidence then, that targeting sleep or insomnia may help to reduce nocturia for some patients, however, studies investigating this approach for treatment of nocturia are scarce. It is reasonable to assume that those patients with a true mismatch between the amount of urine produced overnight and the capacity of the bladder to hold urine overnight (e.g., those with NP) will need to void, and are good candidates for therapy targeting anomalies in these functions. In the absence of such specific knowledge, targeting urinary tract function or sleep itself may both represent viable treatments for nocturia. It should be recognized that older people in particular, who are most likely to be affected by nocturia, are at increased risk of falls and cognitive-related side effects with sleep medication, $, 54,55$ though it is also becoming clear that arising from bed per se during the night may constitute a risk for falls. ${ }^{54,56}$

\section{The partner or caregiver}

The far-reaching negative consequences of sleep disturbances should not be underestimated. Although relatively few studies have examined the impact of sleep disturbance on families and caregivers, those that have investigated this issue consistently report considerable difficulties for partners of people with nocturia. In one survey of partners of men with benign prostatic enlargement, three-quarters were woken up more than once a night by their partner, and nearly half reported being 'tired' the next day because of the frequent awakenings ${ }^{57}$ In another study, sleep was reported to be the area of greatest concern for wives and partners of men with prostate symptoms (identified by using the international prostate symptom score), with $46 \%$ of women waking due to their partner's night-time voiding. ${ }^{58}$ In a recent study in 130 Korean men with nocturia (>1 void) and their spouses, 98\% suffered at least one inconvenience that affected heath-related QoL; sleep disturbance was rated as the most inconvenient. ${ }^{59}$ Sixty-two percent of spouses reported fatigue, and $36 \%$ reported feeling dissatisfied, unhappy, or terrible.

It has been reported that nocturnal problems, including micturition, may contribute to the institutionalization of older relatives. Such difficulties are likely to include episodes of 
nocturnal incontinence, and the association therefore may not be a result of nocturia alone. However, if patients with nocturia suffer falls and fractures as discussed above, an additional strain is placed on families, both emotionally and practically. Therefore, nocturnal voiding not only has inevitable consequences for the partner's sleep patterns, but may also cause additional difficulties and distress for the household.

\section{Society}

Health-economic studies in relation to urology, and specifically to nocturia and its treatment, are in their infancy, and more analyses are needed to fully evaluate the cost of nocturia and its impact on sleep for society, and the economic implications of appropriate therapy. As part of an analysis of the impact of nocturia on functioning and QoL, a prospective Swedish study reported that individuals with nocturia had $9.2 \%$ greater overall work-impairment than controls; this was estimated to represent an indirect cost of $9.2 \%$ of the annual income. The loss of QoL caused by disease can be numerically represented in terms of quality-adjusted life years (QALYs), which are a measure of both quantity and quality of life, with one full QALY representing perfect health, and 0 representing death. Increasing severity of nocturia was associated with a decrease in QALYs. ${ }^{22}$ Thus, using a multiple regression analysis, each additional void would equate to a decrease of 0.027 QALYs per year.

The cost-effectiveness of strategies to address nocturia is dependent on the etiology of nocturia and the selection of appropriate therapy. Using the above estimates of the reduction in QALYs with nocturia to gauge the cost-effectiveness of one possible therapy antidiuretic treatment for nocturia in patients with $\mathrm{NP}$ - it was calculated that the clinical benefits of symptom improvement translated to QALY gains of 0.03 for both men and women. ${ }^{22}$ In addition, a preliminary analysis of data from published sources comparing the cost-effectiveness of behavioural changes versus antidiuretic treatment indicated that, although the direct costs of pharmacological therapy may be greater than the costs of behavioural changes, ${ }^{60}$ antidiuretic treatment of nocturia with NP was associated with increased productivity and QoL. ${ }^{60}$ Cost-effectiveness studies of other therapies such as anticholinergics exist, but few focus on the impact specifically of nocturia, disturbed sleep, and improvements in these nocturnal parameters since symptoms of urgency and frequency are generally considered primary in patients with overactive bladder. ${ }^{61}$ While further studies are needed, available data support the high societal costs of sleep disturbance, and highlight the need for effective treatment, appropriate to the etiology in the specific patient, to reduce the overall socioeconomic burden.

Behavioural treatment may be appropriate for some etiologies of nocturia, for example in patients with urinary urgency at night or apparent small bladder capacity. Behavioral strategies in these patients can be effective, and the benefit to the patient may be greater than the "cost" with no side effects.

\section{Conclusions}

Sleep plays a vital role in physical and mental functioning. It is increasingly recognized that poor sleep quality is a highly prevalent and chronic condition that merits greater awareness due to the wide-ranging and serious repercussions associated with it. Nocturia is one of the primary causes of sleep disturbance and has been shown to impair functioning, QoL, health and productivity, with those experiencing two or more voids per night reporting significant 'bother'. Many urologists have assumed that if nocturia does not overtly 'bother' the individual, then the ultimate significance of these interruptions from sleep are dubious. As we have shwn in this paper, disregarding the potential consequences of nocturia are misguided and ignore current literature. By comparison, one would never ignore treatment of hypertension because the patient was not bothered by his or her symptoms. Nocturia 
warrants full consideration as a significant target for intervention, aiming to reduce the burden of poor sleep quality on individuals, families and society.

\section{Abbreviations}

$\begin{array}{ll}\text { CI } & \text { confidence interval } \\ \text { HR } & \text { hazard ratio } \\ \text { KHQ } & \text { King's Health Questionnaire } \\ \text { NP } & \text { nocturia polyuria } \\ \text { N-QoL } & \text { nocturia-specific quality of life } \\ \text { OR } & \text { odds ratio } \\ \text { PSQI } & \text { Pittsburgh Sleep Quality Index } \\ \text { QALYs } & \text { quality-adjusted life years } \\ \text { QoL } & \text { quality of life }\end{array}$

\section{Glossary}

a-blockers

Anticholinergics (or antimuscarinics)

\section{Benign prostatic obstruction}

Desmopressin

\section{Quality-adjusted life year}

\author{
Nocturia \\ Nocturnal polyuria
}

these medications relax muscle fibres that control tension in the prostate gland and bladder. They can reduce the pressure on the urethra and increase the flow of urine in patients with benign prostatic obstruction

a class of medications that inhibit parasympathetic nerve impulses by selectively blocking the binding of the neurotransmitter acetylcholine to its receptor in nerve cells. These cells can be responsible for involuntary movements of smooth muscles present in the urinary tract, causing overactive bladder

generally caused by a benign enlargement of the prostate gland, which can exert pressure on the urethra and cause problems with urination

a synthetic analogue of arginine vasopressin (see glossary), which has greater antidiuretic potency, and no pressor effects; used in the treatment of nocturia due to nocturnal polyuria

a measure of disease burden, taking into account the quality and the quantity of life; used to assess the value for money offered by medical intervention, with a value of 1.0 assigned to each year in perfect health, and a value of 0.0 used for death

Number of nocturnal bathroom visits, defined by the International Consultation on Incontinence as one or more voids per night

production of an abnormally large volume of urine at night (including the first morning void). Defined as $>20-33 \%$ of the daily total volume (for younger and older adults respectively) naturally-occurring antidiuretic hormone which concentrates urine and reduces urinary output; it has additional pressor effects 


\section{Reference List}

(1). Blackwell T, Yaffe K, Ancoli-Israel S, Schneider JL, Cauley JA, Hillier TA, et al. Poor sleep is associated with impaired cognitive function in older women: the study of osteoporotic fractures. J Gerontol A Biol Sci Med Sci. Apr; 2006 61(4):405-10. [PubMed: 16611709]

(2). Stone KL, Ewing SK, Lui LY, Ensrud KE, Ancoli-Israel S, Bauer DC, et al. Self-reported sleep and nap habits and risk of falls and fractures in older women: the study of osteoporotic fractures. J Am Geriatr Soc. Aug; 2006 54(8):1177-83. [PubMed: 16913982]

(3). Dam TT, Ewing S, Ancoli-Israel S, Ensrud K, Redline S, Stone K. Association between sleep and physical function in older men: the osteoporotic fractures in men sleep study. J Am Geriatr Soc. Sep; 2008 56(9):1665-73. [PubMed: 18759758]

(4). Stone KL, Ancoli-Israel S, Blackwell T, Ensrud KE, Cauley JA, Redline S, et al. Actigraphymeasured sleep characteristics and risk of falls in older women. Arch Intern Med. Sep 8; 2008 168(16):1768-75. [PubMed: 18779464]

(5). Stone KL, Ewing SK, Ancoli-Israel S, Ensrud KE, Redline S, Bauer DC, et al. Self-reported sleep and nap habits and risk of mortality in a large cohort of older women. J Am Geriatr Soc. Apr; 2009 57(4):604-11. [PubMed: 19220560]

(6). American Psychiatric Association. Diagnostic and Statistical Manual of Mental Disorders - Text Revision. 4th ed. American Psychiatric Publishing Inc; Washington, DC: 2000.

(7). Culpepper L. Secondary insomnia in the primary care setting: review of diagnosis, treatment, and management. Curr Med Res Opin. Jul; 2006 22(7):1257-68. [PubMed: 16834824]

(8). Ohayon MM. Nocturnal awakenings and comorbid disorders in the American general population. J Psychiatr Res. Nov; 2008 43(1):48-54. [PubMed: 18374943]

(9). National Institutes of Health State of the Science Conference statement on Manifestations and Management of Chronic Insomnia in Adults, June 13-15, 2005. Sleep. Sep 1; 2005 28(9):1049_ 57. [PubMed: 16268373]

(10). Bliwise DL, Foley DJ, Vitiello MV, Ansari FP, Ancoli-Israel S, Walsh JK. Nocturia and disturbed sleep in the elderly. Sleep Med. Aug 12.2008 10:540-8. [PubMed: 18703381]

(11). Van Kerrebroeck P, Abrams P, Chaikin D, Donovan J, Fonda D, Jackson S, et al. The standardisation of terminology in nocturia: report from the Standardisation Sub-committee of the International Continence Society. Neurourol Urodyn. 2002; 21(2):179-83. [PubMed: 11857672]

(12). Cai T, Gardener N, Abraham L, Boddi V, Abrams P, Bartoletti R. Impact of surgical treatment on nocturia in men with benign prostatic obstruction. BJU Int. Oct; 2006 98(4):799-805. [PubMed: 16978275]

(13). Drake NL, Flynn MK, Romero AA, Weidner AC, Amundsen CL. Nocturnal polyuria in women with overactive bladder symptoms and nocturia 1. Am J Obstet Gynecol. May; 2005 192(5): 1682-6. [PubMed: 15902177]

(14). Yoshimura K, Terai A. Fluctuation of night time frequency in patients with symptomatic nocturia. Int J Urol. May; 2005 12(5):469-73. [PubMed: 15948746]

(15). Yu HJ, Chen FY, Huang PC, Chen TH, Chie WC, Liu CY. Impact of nocturia on symptomspecific quality of life among community-dwelling adults aged 40 years and older. Urology. Apr; 2006 67(4):713-8. [PubMed: 16566966]

(16). Stanley N. The Underestimated Impact of Nocturia on Quality of Life. European Urology Supplements. 2005; 4(7):17-9.

(17). Ancoli-Israel S. The impact and prevalence of chronic insomnia and other sleep disturbances associated with chronic illness. American Journal of Managed Care. 2006; 12:S221-S229. [PubMed: 16686592]

(18). Irwin DE, Milsom I, Hunskaar S, Reilly K, Kopp Z, Herschorn S, et al. Population-Based Survey of Urinary Incontinence, Overactive Bladder, and Other Lower Urinary Tract Symptoms in Five Countries: Results of the EPIC Study. Eur Urol. Dec; 2006 50(6):1306-15. [PubMed: 17049716]

(19). Hetta J. The impact of sleep deprivation caused by nocturia. BJU Int. Dec; 1999 84(Suppl 1):278. [PubMed: 10674891] 
(20). Hernandez FC, Ristol PJ, Estivill E, Miranda JE Batista, Aramburu MA Lopez. [Importance of nocturia and its impact on quality of sleep and quality of life in patient with benign prostatic hyperplasia]. Actas Urol Esp. Mar; 2007 31(3):262-9. [PubMed: 17658155]

(21). Fiske J, Scarpero HM, Xue X, Nitti VW. Degree of bother caused by nocturia in women. Neurourol Urodyn. 2004; 23(2):130-3. [PubMed: 14983424]

(22). Kobelt G, Borgstrom F, Mattiasson A. Productivity, vitality and utility in a group of healthy professionally active individuals with nocturia. BJU Int. Feb; 2003 91(3):190-5. [PubMed: 12581002]

(23). Bing MH, Moller LA, Jennum P, Mortensen S, Skovgaard LT, Lose G. Prevalence and bother of nocturia, and causes of sleep interruption in a Danish population of men and women aged 60-80 years. BJU Int. Sep; 2006 98(3):599-604. [PubMed: 16827903]

(24). Carskadon MA. Sleep deprivation: health consequences and societal impact. Med Clin North Am. May; 2004 88(3):767-76. [PubMed: 15087215]

(25). Williamson AM, Feyer AM. Moderate sleep deprivation produces impairments in cognitive and motor performance equivalent to legally prescribed levels of alcohol intoxication. Occup Environ Med. Oct; 2000 57(10):649-55. [PubMed: 10984335]

(26). Nakagawa H, Ikeda Y, Niu K, Kaiho Y, Ohmori-Matsuda K, Nakaya N, et al. Does nocturia increase fall-related fractures and mortality in a community-dwelling elderly population aged 70 years and over? Results of a 3-year prospective cohort study in Japan. Neurourol Urodyn. 2008; 27:674-5.

(27). Asplund R. Hip fractures, nocturia, and nocturnal polyuria in the elderly. Arch Gerontol Geriatr. Nov; 2006 43(3):319-26. [PubMed: 16457897]

(28). Temml C, Ponholzer A, Gutjahr G, Berger I, Marszalek M, Madersbacher S. Nocturia is an ageindependent risk factor for hip-fractures in men. Neurourol Urodyn. Mar 19; 2009 28(8):949-52. [PubMed: 19301408]

(29). van Dijk L, Kooij DG, Schellevis FG. Nocturia in the Dutch adult population. BJU Int. Nov; 2002 90(7):644-8. [PubMed: 12410740]

(30). Asplund R, Aberg HE. Nocturia and health in women aged 40-64 years. Maturitas. May 29; 2000 35(2):143-8. [PubMed: 10924840]

(31). Oztura I, Kaynak D, Kaynak HC. Nocturia in sleep-disordered breathing. Sleep Med. Jun; 2006 7(4):362-7. [PubMed: 16564213]

(32). Ferrie JE, Shipley MJ, Cappuccio FP, Brunner E, Miller MA, Kumari M, et al. A prospective study of change in sleep duration: associations with mortality in the Whitehall II cohort. Sleep. Dec 1; 2007 30(12):1659-66. [PubMed: 18246975]

(33). Knutson KL. Impact of sleep and sleep loss on glucose homeostasis and appetite regulation. Sleep Med Clin. Jun; 2007 2(2):187-97. [PubMed: 18516218]

(34). Nakagawa H, Ikeda Y, Niu K, Kaiho Y, Ohmori-Matsuda K, Nakaya N, et al. Association between nocturia and mortality in a community-dwelling elderly population aged 70 years and over: results of a 3-year prospective cohort study in Japan. J Urol. 2009; 181:8.

(35). Endeshaw YW, Johnson TM, Kutner MH, Ouslander JG, Bliwise DL. Sleep-disordered breathing and nocturia in older adults. J Am Geriatr Soc. Jun; 2004 52(6):957-60. [PubMed: 15161461]

(36). Margel D, Lifshitz D, Brown N, Lask D, Livne PM, Tal R. Predictors of nocturia quality of life before and shortly after prostatectomy. Urology. Sep; 2007 70(3):493-7. [PubMed: 17905104]

(37). Djavan B, Milania S, Davies J, Bolodeokub J. The impact of tamsulosin oral controlled absorption system (OCAS) on nocturia and the quality of sleep. European Urology Supplements. 2005; 4:61-8.

(38). van Kerrebroeck PE, Rezapour M, Cortesse A, Thuroff J, Riis A, Norgaard JP. Desmopressin in the treatment of nocturia: a double-blind, placebo-controlled study. Eur Urol. Jul; 2007 52(1): 221-9. [PubMed: 17280773]

(39). Hill S, Khullar V, Wyndaele JJ, Lheritier K. Dose response with darifenacin, a novel once-daily M3 selective receptor antagonist for the treatment of overactive bladder: results of a fixed dose study. Int Urogynecol J Pelvic Floor Dysfunct. May; 2006 17(3):239-47. [PubMed: 15999217] 
(40). Garely AD, Lucente V, Vapnek J, Smith N. Solifenacin for overactive bladder with incontinence: symptom bother and health-related quality of life outcomes. Ann Pharmacother. Mar; 2007 41(3):391-8. [PubMed: 17341526]

(41). Kelleher CJ, Reese PR, Pleil AM, Okano GJ. Health-related quality of life of patients receiving extended-release tolterodine for overactive bladder. Am J Manag Care. Dec; 2002 8(19 Suppl):S608-S615. [PubMed: 12516955]

(42). Wein AJ. How much is enough and who says so? The case of the King's Health Questionnaire and overactive bladder. J Urol. Mar.2005 173(3):908.

(43). Weiss J. Prevalence of nocturnal polyuria in nocturia. J Urol. 2009; 181:538.

(44). Norgaard JP, Hashim H, Malmberg L, Robinson D. Antidiuresis therapy: mechanism of action and clinical implications. Neurourol Urodyn. May 4.2007

(45). Margel D, Shochat T, Getzler O, Livne PM, Pillar G. Continuous positive airway pressure reduces nocturia in patients with obstructive sleep apnea. Urology. May; 2006 67(5):974-7. [PubMed: 16635510]

(46). FitzGerald MP, Mulligan M, Parthasarathy S. Nocturic frequency is related to severity of obstructive sleep apnea, improves with continuous positive airways treatment. Am J Obstet Gynecol. May; 2006 194(5):1399-403. [PubMed: 16579944]

(47). Lose G, Lalos O, Freeman RM, Van Kerrebroeck P. Efficacy of desmopressin (Minirin) in the treatment of nocturia: a double-blind placebo-controlled study in women. Am J Obstet Gynecol. Oct; 2003 189(4):1106-13. [PubMed: 14586363]

(48). Mattiasson A, Abrams P, Van Kerrebroeck P, Walter S, Weiss J. Efficacy of desmopressin in the treatment of nocturia: a double-blind placebo-controlled study in men. BJU Int. Jun; 2002 89(9): 855-62. [PubMed: 12010228]

(49). Lose G, Mattiasson A, Walter S, Lalos O, Van Kerrebroeck P, Abrams P, et al. Clinical experiences with desmopressin for long-term treatment of nocturia. J Urol. Sep; 2004 172(3): 1021-5. [PubMed: 15311028]

(50). Asplund R, Sundberg B, Bengtsson P. Oral desmopressin for nocturnal polyuria in elderly subjects: a double-blind, placebo-controlled randomized exploratory study. BJU Int. Apr; 1999 83(6):591-5. [PubMed: 10233563]

(51). Song YS, Ku JH. Zolpidem pharmacotherapy combined with alpha-blocker therapy for nocturia unresponsive to alpha-blocker monotherapy in men with lower urinary tract symptoms: a preliminary study. Int Urol Nephrol. 2007; 39(4):1147-52. [PubMed: 17610040]

(52). Sugaya K, Nishijima S, Owan T, Oda M, Miyazato M, Ogawa Y. Effects of walking exercise on nocturia in the elderly. Biomed Res. Apr; 2007 28(2):101-5. [PubMed: 17510495]

(53). King AC, Pruitt LA, Woo S, Castro CM, Ahn DK, Vitiello MV, et al. Effects of moderateintensity exercise on polysomnographic and subjective sleep quality in older adults with mild to moderate sleep complaints. J Gerontol A Biol Sci Med Sci. Sep; 2008 63(9):997-1004. [PubMed: 18840807]

(54). Stone KL, Ensrud KE, Ancoli-Israel S. Sleep, insomnia and falls in elderly patients. Sleep Med. Sep; 2008 9(Suppl 1):S18-S22. [PubMed: 18929314]

(55). Glass J, Lanctot KL, Herrmann N, Sproule BA, Busto UE. Sedative hypnotics in older people with insomnia: meta-analysis of risks and benefits. BMJ. Nov 19.2005 331(7526):1169. [PubMed: 16284208]

(56). Brassington GS, King AC, Bliwise DL. Sleep problems as a risk factor for falls in a sample of community-dwelling adults aged 64-99 years. J Am Geriatr Soc. Oct; 2000 48(10):1234-40. [PubMed: 11037010]

(57). Sells H, Donovan J, Ewings P, MacDonagh RP. The development and validation of a quality-oflife measure to assess partner morbidity in benign prostatic enlargement. BJU Int. Mar; 2000 85(4):440-5. [PubMed: 10691823]

(58). Shvartzman P, Borkan JM, Stoliar L, Peleg A, Nakar S, Nir G, et al. Second-hand prostatism: effects of prostatic symptoms on spouses' quality of life, daily routines and family relationships. Fam Pract. Dec; 2001 18(6):610-3. [PubMed: 11739347]

(59). Kim SC, Lee SY. Men's lower urinary tract symptoms are also mental and physical sufferings for their spouses. J Korean Med Sci. Apr; 2009 24(2):320-5. [PubMed: 19399278] 
(60). Holm-Larsen T, Sorensen J, Hansen EH, Norgaard JP. Desmopressin is more cost effective than behavioural treatment in adults suffering from nocturia when applying a societal perspective. $\mathrm{J}$ Urol. 2008; 179(suppl):56. Ref Type: Abstract.

(61). Cardozo L, Thorpe A, Warner J, Sidhu M. The cost-effectiveness of solifenacin vs fesoterodine, oxybutynin immediate-release, propiverine, tolterodine extended-release and tolterodine immediate-release in the treatment of patients with overactive bladder in the UK National Health Service. BJU Int. Feb 3.2010 
Practice points

- Chronic insomnia complaints are very frequent among older adults with nocturia, particularly difficulty falling asleep, fewer total hours of sleep, and difficulty falling back to sleep.

- Nocturia is an independent predictor of insomnia and deterioration of sleep quality

- Sleep apnea is associated with increased nocturia.

- Nocturia is also known to impair functioning, quality of life and productivity.

- Patients with two or more voids a night have a higher risk of mortality after controlling for co-morbidities

- In patients with insomnia co-morbid with nocturia, health care professionals should consider concurrent intervention for both conditions. 
Research agenda

Future research priorities for understanding the relationship between sleep and nocturia should include studies:

- To determine the most appropriate endpoint or outcome measure when evaluating the effect of nocturia and nocturia treatment on sleep.

- To evaluate whether treating insomnia in the absence of treating nocturia decreases the number of voids per night.

- To evaluate whether treating nocturia in the absence of treating insomnia improves sleep. 


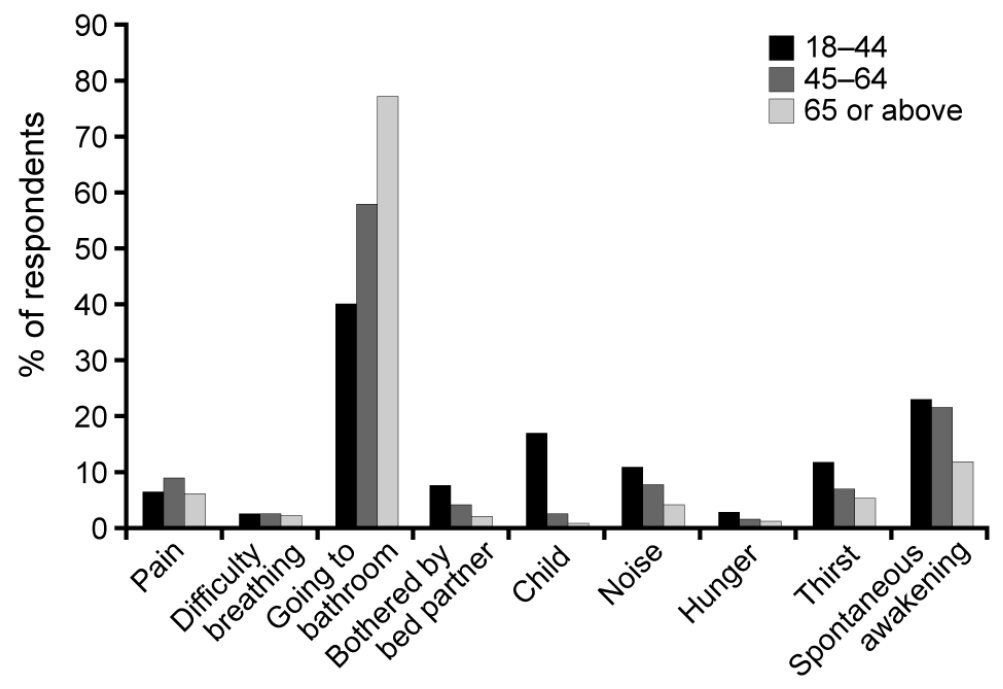

Figure 1.

Reasons for nocturnal awakenings among the US general population by age group*8 *All reasons were cited as 'often'. 


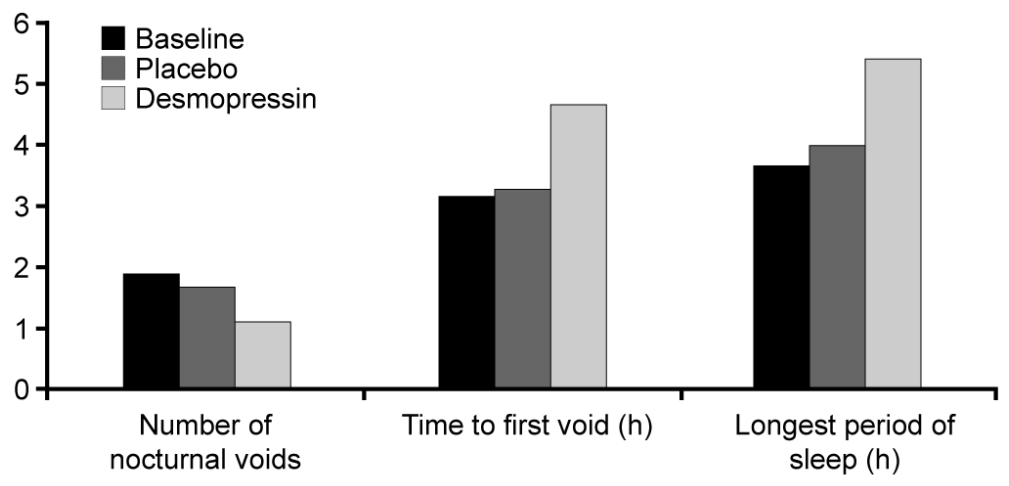

After 2 weeks of treatment

Figure 2.

Effects of desmopressin treatment on voiding frequency and sleep fragmentation in elderly patients with nocturnal polyuria $(N=17)^{49}$ 